\title{
TRADITIONAL VERSUS OPEN UNIVERSITY TEACHING METHODS: A COST COMPARISON
}

\author{
BRUCE LAIDLAW and RICHARD LAYARD* \\ Higher Education Research Unit, London School of Economics and Political Science, \\ Houghton Street, London WC2A 2AE, United Kingdom
}

\begin{abstract}
The paper attempts to throw light on the direct (instructional) cost of OU teaching methods as against conventional "live" instruction. The variable cost per student-course is with one exception lower in the OU than elsewhere. This constitutes a strong case for the use of existing OU packages in campus universities, especially as campus universities might feel able to dispense with the costs of the summer schools. It also constitutes a case for expansion of existing courses at the OU. As regards the development of new OU packages, the paper shows the Foundation courses to be much cheaper than equivalent provision de novo at the same scale in campus universities. Measured by the breakeven number of students, second-level courses in a given faculty are cheaper than foundation level courses. But they also have fewer students and some are operating at levels which, if there were no interdependence between courses, might be considered expensive. If however they were used by more students either at the OU or at campus universities they could be economic, even when taken on their own. The paper does not cost student time but, if this is cheaper when OU teaching methods are used, this is a further argument in their favour.
\end{abstract}

\section{Introduction}

In previous papers Wagner $(1972,1973)$ argued that the Open University has an average cost per full-time-equivalent student one half that of conventional universities. This, he claimed, justified the existence of the university and, given the low ratio of marginal to average costs, its expansion. His study was necessarily aggregative and based on arbitrary assumptions about what the University would be like when it reached a steady state.

\footnotetext{
* This paper reports results of a Joint Project on the Cost-Effectiveness of the Open University undertaken by the Higher Education Research Unit, London School of Economics and the Open University and directed by Richard Layard. The work was planned and discussed by a Steering Group consisting of J. Austin, J. Clinch, B. Francis, D. Hawkridge (Chairman), B. Laidlaw, R. Layard, N. Mcintosh, R. Smith, D. Verry, L. Wagner. The authors are most grateful to the members of the Group for their help and for their comments on an earlier draft. They also wish to thank those others at the $\mathrm{OU}$ and $\mathrm{BBC}$ who have provided information
} 
By contrast the present study attempts to find out the costs, not of the Open University (OU) as a whole, but of the individual courses it actually provides at its present state of development. Such information is important for many reasons. First, it bears on the question of whether the OU should be expanded - if when we compare the marginal costs of OU and traditional courses the OU costs are lower, this provides an argument for extra enrolments in OU courses that already exist. Such extra enrolments could be achieved either by expanding OU enrolments or by using OU courses as part of the offering of campus universities. A quite different question is the creation of new OU courses. This would be justified if, taking into account both the fixed and marginal costs of the course, its enrolment was likely to be sufficient for average costs to be below those in campus universities. It could also be justified of course on the grounds that the new courses were complementary to the existing ones, provided the overall operation were justified and indivisible.

The OU, though founded in 1969, is of course still in process of evolution. Nonetheless, we hope that the cost functions we show, as opposed to the levels of cost which they reflect, bear some relation to those which could be expected in an institution that had been in existence for some time. As we point out in more detail at the end of the paper, at least some of our figures are the creatures of historical circumstance and in these cases lower future costs may be expected for a given output. Even so, the present pattern of costs brings out clearly the economies of scale that are the main feature that distinguishes the costs of Open University methods from those of conventional courses. Before constructing our cost functions (in Part II) and comparing them with those of traditional universities (in Part III) it may be useful to provide a brief description of the OU teaching system and the relation between it and the OU's budget. ${ }^{1}$

\section{OU teaching methods and the OU budget}

An OU degree is built up on the basis of a number of course credits (six for ordinary degrees, eight for honours) and the student may spread the acquisition of course credits over any number of years, though usually at the rate of one credit per year. An OU degree is intended to be general rather than specialist, and courses are organized within faculties rather than departments, with a number of inter-faculty courses. At present students can pursue courses

\footnotetext{
1 We do not discuss the relative effectiveness of courses. The available evidence on the new media used in other contexts suggests that, when substituted for live teaching on a limited scale, the are on average at least as effective as live teaching (Layard, 1973).
} 
in Arts, Social Science, Education, Mathematics, Science and Technology ${ }^{2}$; or can combine courses from more than one faculty. Each faculty, except Education, runs a Foundation Course as an introduction to its disciplines. Students start their degree studies by taking a Foundation course, and must normally take two. They then build up their degree by choosing Second, Third and Fourth Level courses. A full credit course normally lasts 32 to 34 weeks, from January to October and is meant to require about 10 hours study a week. ${ }^{3}$

The teaching system has the following main components.

\section{A. CORRESPONDENCE MATERIALS}

These form the core of the courses. The student's work is organized around a regular package which includes a course unit text for each week together with regular assignments which are either (a) multiple-choice questions marked by computer or (b) less structured problems marked by the individual student's course tutor. The package also includes notes on the TV and radio programmes and various forms of self-assessment tests, but only (a) and (b) enter into the final assessment of the student's performance on the course, together with an examination sat in November. The contents of the package are the responsibility of a Course Team, a group of academics, BBC producers and educational technologists with a senior academic as chairman. Sometimes the correspondence materials are the collective work of the Course Team, hamm6red into shape at lengthy meetings, though more often each text has an identifiable author. Course Teams also make use of consultants with specialist knowledge, brought in to contribute to particular units or, more rarely, co-opted onto the Course Team itself.

\section{B. TV AND RADIO BROADCASTS}

These vary in frequency according to the course but each course unit involves at least one radio or TV broadcast lasting about half an hour. The programmes are designed as an integral part of each course but, except in Science, have not been designated so essential that students unable to receive them should not take the course. For a sample of Foundation Course TV programmes the median percentage of students viewing was about 90 per cent for nonscience programmes and 95 per cent for science; for radio the

\footnotetext{
2 From 1973, the OU is also providing self-contained post-experience courses to provide continuing education for adults. These are outside the degree system and are not considered in this paper.

3 Students on Foundation Courses actually put in on average 12 hours a week per course, and slightly more on Second Level Courses. See Blacklock and Morrison (1972).
} 
corresponding figures were roughly 10 per cent lower (Mcintosh and Morrison, 1972). Programmes are currently produced by the BBC at Alexandra Palace under a special arrangement.

\section{FACE-TO-FACE TEACHING}

Each student has a tutor for each course, as well as a counsellor for his work as a whole. Tutors and counsellors are based on some 260 study centres scattered throughout the country. A study centre is usually in room in a local college or school reserved for OU use in the evenings and sometimes also at weekends. Playback facilities for radio and TV broad- casts are provided, and in many of the study centres a computer terminal has been installed, connected to one of the three university computers which provide the Student Computing Service. Tutors and counsellors are employed part-time by the OU and are usually also staff in higher education establishments: most tutors have abouf 20 OU students on a course.

Tutors do not generally see students individually but hold classes. Attendance is voluntary and some students never go, while others may go to every class, the frequency of classes varying from one hour a week to much less frequent day schools. Contact with counsellors can again be face-to-face or by telephone or correspondence. Taking all reasons for attending study centres (whether to view or listen to programmes, to attend classes or to see counsellors) about 40 per cent of Foundation course students attend in any given week.

The only occasion on which attendance is required for face-to-face teaching is at a one-week summer school, where this is part of the course, as for example in all the Foundation courses and Second Level courses in Mathematics, Science and Technology. Summer schools are held on selected university Campuses over July and August. For the student. Summer School attendance provides a major break with the pattern of isolated study. This has both benefits and costs: on the one hand. Summer School brings together staff and students for a period of intensive study but on the other hand a principal advantage of the OU for a great many of its students is precisely that it does not require full-time residential study. For those at work or with families, time taken from annual holidays may be a severe problem. The direct financial cost is important too; the OU requires the Summer School programme to be selffinancing out of student fees ( $£ 25$ per week at Foundation Level in 1971 and 1972, and $£ 30$ for Second Level courses). Depending on the attitude of his LEA towards grants for Summer School weeks, a student may find this takes up a third or more of the cost of a degree taken with the OU. It is partly for this reason that the OU has sought to restrict the size of the Summer School programme. 


\section{HOME EXPERIMENTAL KITS AND STUDENT COMPUTING SERVICE}

For some science courses, students are loaned specially-designed kits for doing experiments at home, including such sophisticated pieces of equipment as chemical balances and a microscope with 100-fold magnification. ${ }^{4}$ The University has set up a Student Computing Service chiefly for mathematics students, but also available for other faculties. To use the service the student must usually visit a major study centre, where computer terminals have been installed, but he works without personal super- vision as if he was at home. For a few students not within reach of a terminal, a postal computing service has been made available.

\section{OU Budget}

We can now turn to the OU budget so as to identify in a broad way the costs involved in each of these components of the teaching system. In Part II we allocate these various costs much more precisely. Table I shows the university's current budget for 1971 and 1972. The first students were enrolled in January 1971, and in the earlier years current costs were relatively low (June 1969 March 1970: £940,000; April 1970 - December 1970: £2,224,000).

Of the expenditure of roughly $£ 10 \mathrm{~m}$ in 1972 , about one-tenth went on the central academic staff who are responsible for all the components of the OU teaching system, and on their secretarial and technical support. Next in the table we have grouped those outlays mainly connected with correspondence materials (A) - these account for rather under a tenth of the total cost. Then we come to broadcasting (B), accounting for roughly a fifth (mostly TV). As for face-toface teaching (C), its direct cost amounts to about a fifth of total cost, while its administration accounts for over a tenth. Finally, home experimental kits and the student computing service (D) take rather under a tenth, leaving near4y a fifth of the budget for central administration and other items.

\footnotetext{
${ }^{4}$ A student is required to make a returnable deposit of $£ 10$ when he receives his kit.
} 


\section{Table I}

Annual recurrent expenditure

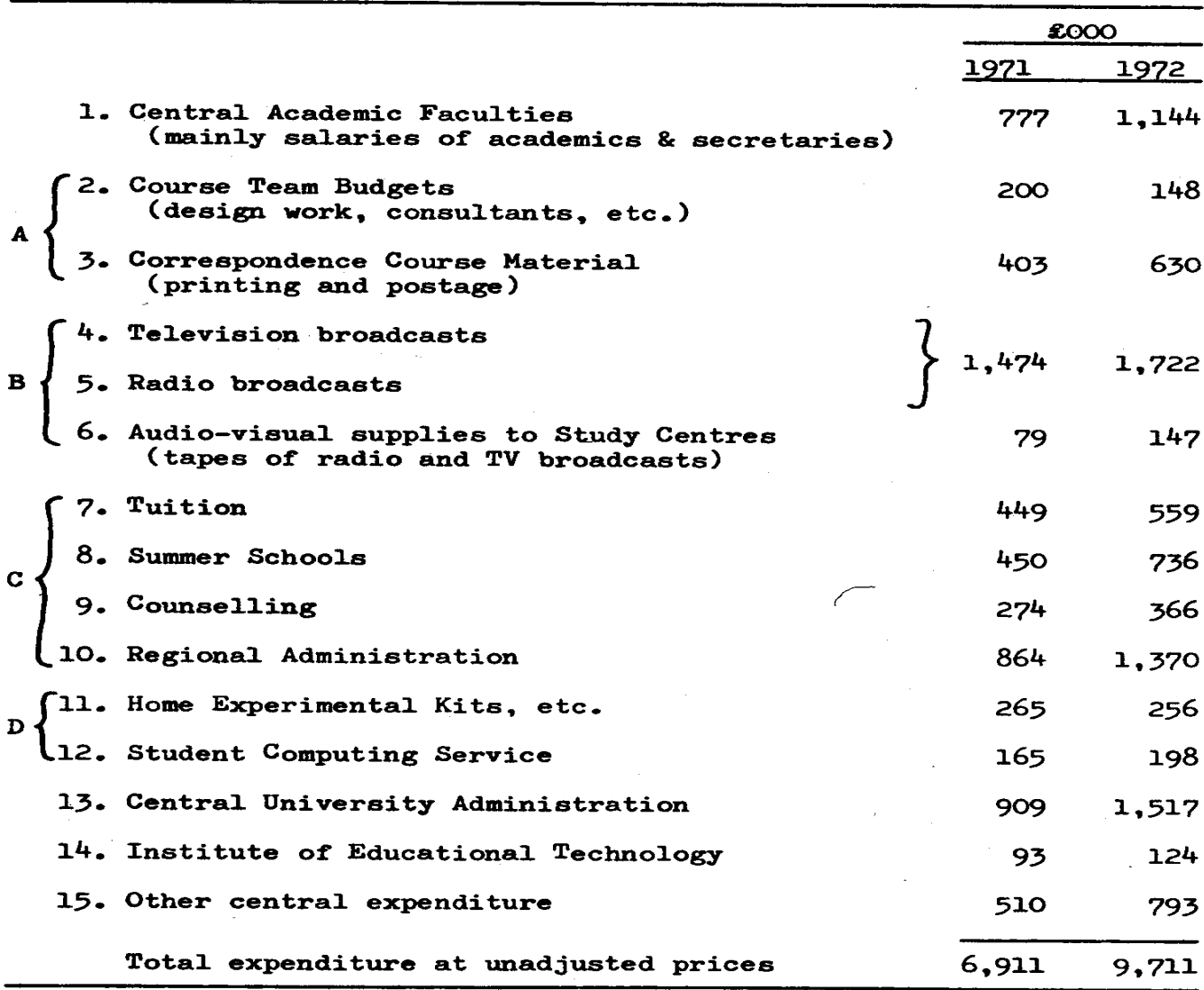

Source: The Open University; Statement of Accounts 1971 and 1972. 
In addition, the University's capital expenditure has been $£ 3,500,000$ in $1969-71$ and $£ 870,000$ in 1972 , mostly on buildings.

\section{Cost functions for each component of cost}

We now want to analyze these costs so as to show how they would vary if more students were enrolled in the university or on individual courses, or if individual courses were dropped or individual components of the package omitted. For this purpose we distinguish between four "types of cost."

\section{COURSE COSTS}

(a) Fixed costs, i.e. costs which are inescapable if the course is put on (shown in Table 2);

(b) Variable costs, i.e. costs which can be altered by altering the number of students on a course (Table 3).

\section{CENTRAL UNIVERSITY COSTS}

(a) Fixed costs, i.e. costs which are inescapable if the OU is to exist (Table 4);

(b) Variable costs, i.e. costs which can be altered by altering the number of students in the university (Table 5).

We assume that variable costs are proportional to the number of students, and offer justification for this belief wherever possible. ${ }^{5}$

\footnotetext{
${ }^{5}$ Mathematically we are saying that the annual resource costs of the OU are Course Costs + Central University Costs, where

Course Costs $=\Sigma_{i}\left(f_{i}+v_{i} S_{i}\right)$ and Central University Costs $=f^{u}+v^{u} S^{u}$ and

$f_{i}=$ annual fixed costs of the $i$ th course, $v_{i}=$ variable costs per student on the $i$ th course, $S_{i}=$ students on the $i$ th course, $f^{t}=$ annual fixed central university costs, $v^{u}=$ variable cost per student in the university, $S^{u}=$ number of students in the university (unequal $\Sigma S_{i}$, since one student can be on two courses)
} 
TABLS 2

Annual fixed cost per course $\mathscr{L}(1971$ prices)

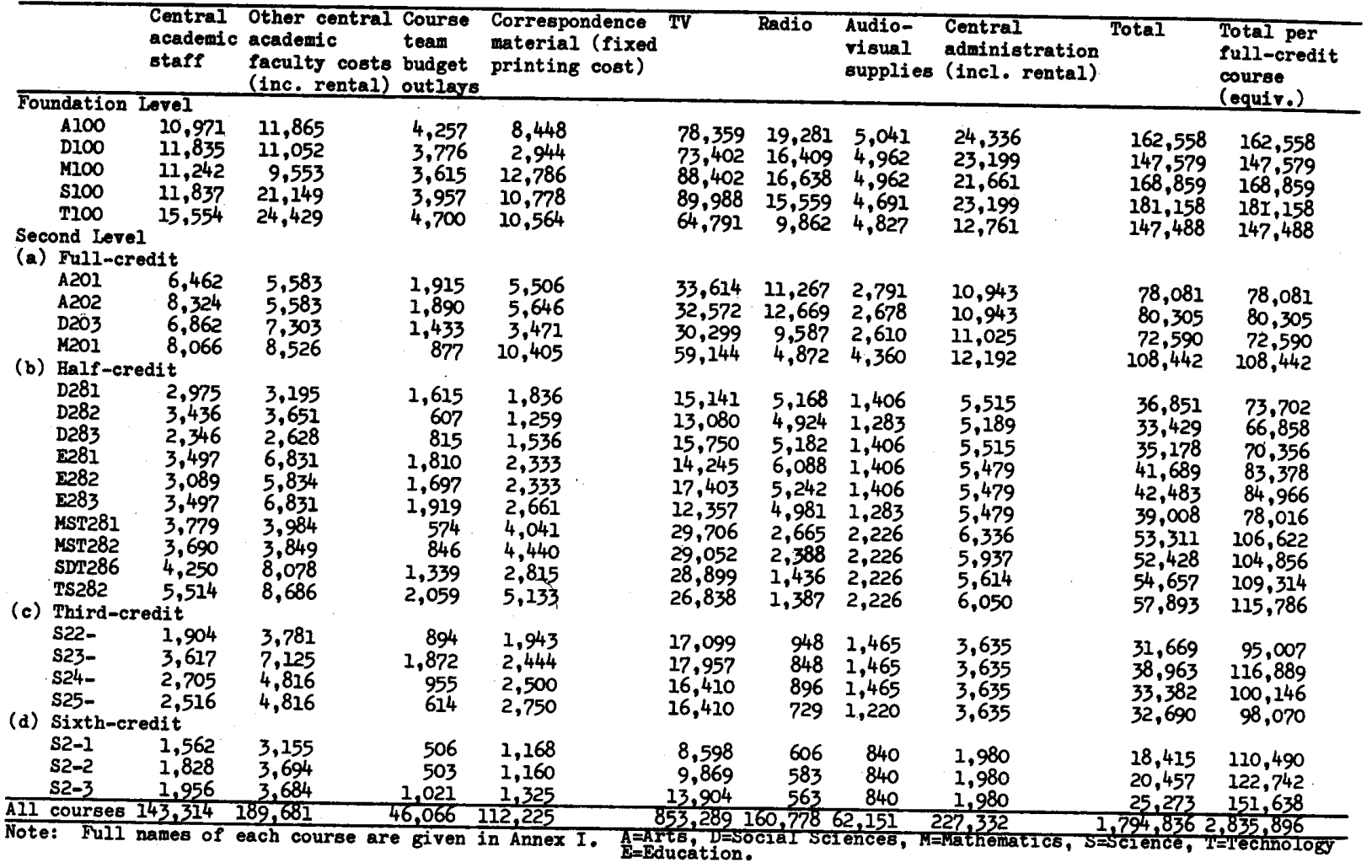


TABLE 3

Annual variable cost per course $\ell$ (1971 prices)

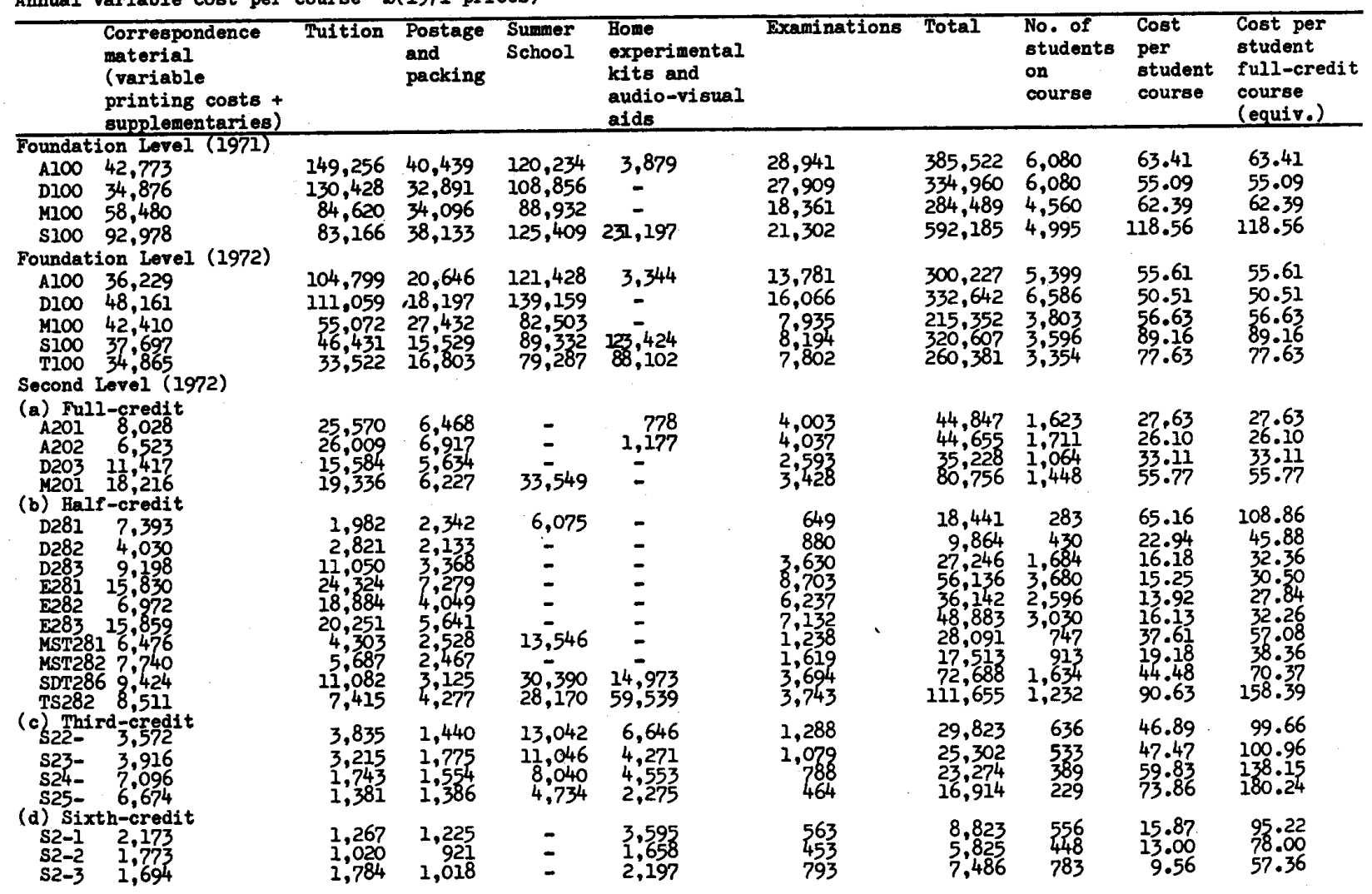


Table 4

Annual fixed central costs

\begin{tabular}{lrr}
\hline & \multicolumn{2}{c}{$\mathcal{E}(1971$ prices) } \\
\cline { 2 - 3 } Central Academic Faculties' administrative contribution & 1971 & \multicolumn{1}{c}{1972} \\
\cline { 2 - 3 } Vice-Chancellors' Office & 52,608 & 59,026 \\
Administrative Secre tariat & 41,933 & 40,839 \\
Administrative Expenses (including Council) & 257,606 & 332,831 \\
Administrative Examinations & 108,105 & 75,022 \\
Information Services & 18,248 & 49,437 \\
Open Forum Broadcasts & 54,737 & 91,076 \\
Data Processing (net of recharged expenditure) & 89,729 & 92,123 \\
Student Computing Service (fixed costs only) & 6,509 & 65,926 \\
Wellingborough Warehouse & 182,355 & 250,610 \\
Institute of Educational Technology & 31,232 & 72,682 \\
Use of furniture and equipment, etc. & 56,937 & 99,245 \\
Rental of premises & 75,846 & 94,543 \\
Maintenance, Transport, Grounds, etc. & 75,240 & 88,077 \\
Miscellaneous & 153,368 & 166,386 \\
& 51,855 & 6,424 \\
Total & & \\
\hline
\end{tabular}

Table 5

Annual variable central costs

\begin{tabular}{lrr}
\hline & \multicolumn{2}{c}{$\mathbf{i}(1971$ prices) } \\
\cline { 2 - 3 } Regional Administration & \multicolumn{1}{c}{1971} & \multicolumn{1}{c}{1972} \\
Counselling & 535,842 & $1,070,337$ \\
Prospectus, Study Guide & 371,566 & 287,864 \\
Student Association, etc. (variable costs) & 6,956 & 14,604 \\
Student Computing Service (var & 9,669 & 15,416 \\
& & 14,953 \\
Number of finally registered students & 943,713 & $1,403,174$ \\
Variable central cost per student & 19,581 & 31,383 \\
\hline
\end{tabular}


The university uses a roughly similar division of course costs (into the Developmental Budget of the course and Direct Student Cost of its annual presentation) but we have aimed at a more sophisticated analysis (e.g. splitting printing costs into fixed and variable elements). Moreover, the fixed annual costs of a course are not the total costs incurred in developing it, but the annual mortgage which, if paid over the life of the course, repays the total costs of development. ${ }^{6}$ This is the concept of fixed course cost used in this paper. Similarly all "capital" costs (e.g. of buildings) are represented by their corresponding annual amortized cost.

We now proceed on this basis to examine each of the "cost components" shown in Table I and allocate it, as well as the University's capital costs, between each of the four "types of cost" in Tables 2-5. When we have done this we shall be able, in Section III, by simple addition to compute the cost functions for each course and for central university costs, and to compare these with those for conventional university courses. All costs are expressed in 1971 prices - using the most relevant sections of the "Brown index." The detailed titles of the courses analysed in Tables 2 and 3 are given in Annex I but the general reader will probably find it enough to know the following key: $A=$ Arts, $\mathrm{D}=$ Social Science, $\mathrm{M}=$ Mathematics, $\mathrm{S}=$ Science, $\mathrm{T}=$ Technology, $\mathrm{E}=$ Education.

\section{Central academic faculties}

The expenditure here comprises mainly the salaries of academic staff and their secretaries, to which must be added an allowance for the rental value of their accommodation, furniture and so on. We begin with academic salaries. These have to be allocated between course preparation, "central" university administration and personal research. In principle, OU staff members have the same amount of time available for research as teachers in other universities, but in practice the pressure of course preparation timetables has hitherto prevented the implementation of the principle on a year by year basis. However, no detailed information is available on the allocation of time by OU staff. For want of it, we assume that their time is allocated in the ratio 60:10:30 between course preparation, central university administration and other activities including

\footnotetext{
6 Thus the annual fixed cost $\left(f_{i}\right)$ of a course which began being made in Year 1 and finished being presented in Year $T$ is given by$$
\sum_{t=1}^{T} \frac{f_{i}}{(1+r)^{t}}=\sum_{t=1}^{T} \frac{C_{t}}{(1+r)^{t}}
$$

where $C_{t}$ are the costs actually incurred in year $t$ and $r$ is the relevant real interest rate. In the present study the interest rate is taken as $5 \%$, the costs are found to be incurred only in Years 1 and 2 and the presentation is assumed to last during years 3-6 inclusive.
} 
research. This compares with the ratio of $66: 34$ between teaching and research, reported by teachers in campus universities with respect to their annual internal "allocable" time. (Committee of Vice-Chancellors and Principals, 1972). The OU figure assumed for research may be somewhat high, but affects the final estimates comparatively little.

To determine the academic staff costs of each course, as shown in Table 2 , we take $60 \%$ of each faculty member's salary cost in each year and allocate the cost to the course for which the teacher is working. Where a staff member worked $x$ months of the year on one course $(A)$ and $y$ months on another course $(B)$, the annual cost is divided between course $A$ and $B$ in the ratio $(x-y+12):(y-$ $x+12$ ). This assumes that during any period of overlap, time is divided equally between the courses. As for the cost of other uses of staff time, administrative time is allocated to fixed central costs (in Table 4) and research time is ignored as independent of the OU teaching operation.

Turning to current faculty costs other than academic salaries, these are allocated in proportion to academic salaries. To these is added the rental value of accommodation used by faculty. This raises a problem of a kind that crops up a number of times in this study. In this case, the quality of accommodation varied widely between the different faculties in the period studied due entirely to historical accident. Since we are mainly interested in long-run costs of an OU type operation we disregard such fortuitous differences. On the other hand, we wish our figures to remain firmly based in OU data and therefore make no judgement about which standard of accommodation is optimal; we merely take the average cost. Wherever short-run historical factors exert major influences on any of our succeeding estimates we shall say so.

\section{Course team budgets}

Course team budgets mainly cover payments for art and design work on correspondence course units (based on an internal pricing system used by the university) and also for consultants who contribute to the course units. No adjustments have been to the expenditure figures for these items.

\section{Correspondence course materials}

The annual cost of these shown in Table I consists of printing (net of additions to stocks) and postal charges. However, for analysing the long- run printing costs of a course we need a more elaborate analysis that distinguishes between the fixed course costs of compositing, machine preparation and the like and the variable cost that varies with the number of copies printed. The existence of economies of scale arising from high fixed costs is well-known in printing and has led the OU to order more than one year's supply at a time. In addition, there may be further economies (or diseconomies) of scale arising from falls (or rises) in the marginal cost per copy. The regression analysis 
reported in Annex II suggests in fact that marginal costs are constant at 17p per book of 100 pages and pro rata for other sizes of books. ${ }^{7}$ Fixed costs fora 100 page book are approximately:

Arts $\quad 1,330$

Social Sciences $\quad 1,060$

Education $\quad 1,140$

Mathematics 2,240

Science $\quad 1,730$

Technology 2,290

Of these fixed costs $£ 510$ are invariant with respect to the size of book and the remainder vary pro rata.

In deriving the costs of OU teaching from these data one should in principle take into account the marketing surplus from commercial sales of course units. The upper bound to the net fixed cost is the total fixed cost less the marketing surplus. ${ }^{8}$ But unfortunately, complete data on the marketing surplus are not currently available and against them eventually must be set the cost of all unused stock. ${ }^{9}$ In Tables 2 and 3, therefore, we simply use the fixed costs and marginal costs from our cost function.

\section{4, 5, 6. Television, radio and audio-visual supplies}

These are all treated as fixed course costs. The BBC have supplied a breakdown by course. Taking 1970, 1971 and 1972 together (at 1971 prices) expenditure has been as follows: ${ }^{10}$

\footnotetext{
7 The form of function used in deriving the following figures is:

Costs $=a_{0}+a_{1} P+a_{2} P R+a_{3} P D$

where $P$ is number of pages per copy; $R$ is number of copies in the print run; and $D$ is a faculty dummy.

8 The reasoning is this. If the cost function is

$\mathrm{C}=\mathrm{b}_{0}+\mathrm{b}_{\mathrm{i}} \mathrm{R}$

the costs are justified if

$\mathrm{V}_{\mathrm{s}}+\mathrm{V}_{\mathrm{u}}>\mathrm{C}=\mathrm{b}_{\mathrm{b}}+\mathrm{b}_{\mathrm{l}} \mathrm{Rs}+\mathrm{b}_{\mathrm{l}} \mathrm{R}_{\mathrm{u}}$

where $\mathrm{V}$ indicates value and subscripts $\mathrm{s}$ and $\mathrm{u}$ indicate sales and university uses respectively. Rewriting the condition we have

$\mathrm{V}_{\mathrm{u}}>\mathrm{b}_{0}-\left(\mathrm{V}_{\mathrm{s}}-\mathrm{b}_{1} \mathrm{R}_{\mathrm{s}}\right)+\mathrm{b}_{1} \mathrm{R}_{\mathrm{u}}$

The term in brackets is at least as large as the marketing surplus.

9 To the end of 1972, the accumulated marketing surplus totalled $£ 50,400$ and provision for obsolete stocks of course units $£ 75,000$.

10 Not shown are fees to performers for repeats of broadcasts. (TV £60,000; Radio £29,000). Each programme is presented twice in each year that a course is presented. So if the course is presented for 4 years there are 7 repeats. Hence, in Table 2, it is assumed for each course that repeat fees in any presentation year equal $7 / 4$ of repeat fees per broadcast. We also assume that a uniform $10 \%$ of programmes for each course are remade during the life of the course.
} 


\begin{tabular}{lrr}
\hline Production & \multicolumn{1}{c}{ TV } & \multicolumn{1}{c}{ Radio } \\
\hline Costs & $£ 2,592$ & $£ 291,5$ \\
&, 000 & 00 \\
No. of programmes made & 508 & 503 \\
Cost per programme & $£ 5,100$ & $£ 580$ \\
Transmission. & & \\
Cost per broadcast & $£ 89$ & $£ 63$ \\
\hline
\end{tabular}

As can be seen, the production costs of a 25-minute television programme were nearly ten times as great as for radio - over $£ 5,000$ as against under $£ 600$. By contrast, annual transmission costs per programme are small and similar for radio and television. (The OU is charged only the marginal transmission cost of its programmes.)

\section{7, 8. Tuition and summer schools}

A student has a separate tutor for each course, so tuition costs appear as variable course costs in Table 3. Tutorial classes are organized in a myriad of ways and no general formula applies. Tutors are also paid for each assignment they mark. As for Summer Schools (for courses which provide them) the main cost (between 50-60\%) is the cost of residence, the other main item being parttime tutors (nearly $20 \%$ ).

\section{9, 10. Counselling and regional administration}

Each student has a counsellor irrespective of how many courses he is taking, so the cost of counselling depends in the long run on the number of students in the university. It is thus a variable central cost and appears in Table 5 . Each counsellor is paid for a weekly $21 / 2$-hour session at his study centre ( $£ 6.25$ in 1971), when his students are free to visit him as they please. ${ }^{11}$ The average number of students per counsellor was 17 in 1971, and the costs of counselling are taken as directly proportional to the number of students. ${ }^{12}$ For want of a better procedure, we make the same assumptions about regional administration.

\section{1, 12. Home experimental kits and student computing service}

The costs of home experimental kits have been treated as variable

\footnotetext{
${ }^{11}$ In future, counsellors will also be paid a fee per student.

12 Annualcosts $=$ Fee per session $\mathrm{x} \frac{\text { Students }}{\text { Students/Counsellors }} \times$ Weeks per year.

Since 1971, the OU has allowed the number of students per counsellor to rise
} 
course costs by adding an annual allowance for depreciation of equipment to the costs of nonreturnable items in the kits. We can make no allowance for nonproportionality in the production of kit equipment. The student computing service is currently working with excess capacity, so that it is more confusing than helpful to allocate its high fixed costs to the courses which use it. Therefore we treat the service as a central university facility and allocate its costs accordingly.

\section{Central university administration}

In general, this is treated as a fixed central cost except where the administrative activity clearly relates to course production. Thus the university library, publishing division and bursary (concerned with purchasing and cost control) are treated as fixed course costs, while examinations and correspondence services (who despatch course material to students) are treated as variable course costs.

\section{4, 15. Institute of Educational Technology, etc.}

The cost of the IET is divided between fixed course costs (to allow for IET members of course teams) and fixed central costs, reflecting the Institute's concern with institutional studies on the Open University. All other unallocated expenditure is included in this table.

In Tables 2 and 3 we total up the fixed and variable costs per course and in Tables 4 and 5 the fixed and variable central costs. Tables 2 and 3 include a final column in which costs of part-credit courses are adjusted to cost per fullcredit-equivalent course. To do this all costs of a course giving a fraction $a$ of credit (other than summer school costs) are multiplied by $1 / \ll$.

\section{The comparison of costs}

\section{METHOD}

We can now proceed to assemble the overall costs of each course and to compare them with the departmental costs in campus universities, (see Table 6). We do the same for central costs in Table 7.

We should begin by pointing out that the comparison in these tables is not exhaustive. First it ignores the cost of student time which is very much higher in campus universities. However, this does not matter in so far as the purpose of the comparison is to throw light on the cost of using OU-type materials in campus universities, for in that case the cost of students' time is a 
fixed element in the situation. Our comparison also omits some other smaller costs borne by students, such as books and travel. Here the OU cost may be higher but again the comparison is only relevant if one is trying to evaluate the OU, which we are not, rather than its teaching system, which we are.

TABLE 6

OU course costs and course costs in campus universities 2 (1971 prices)

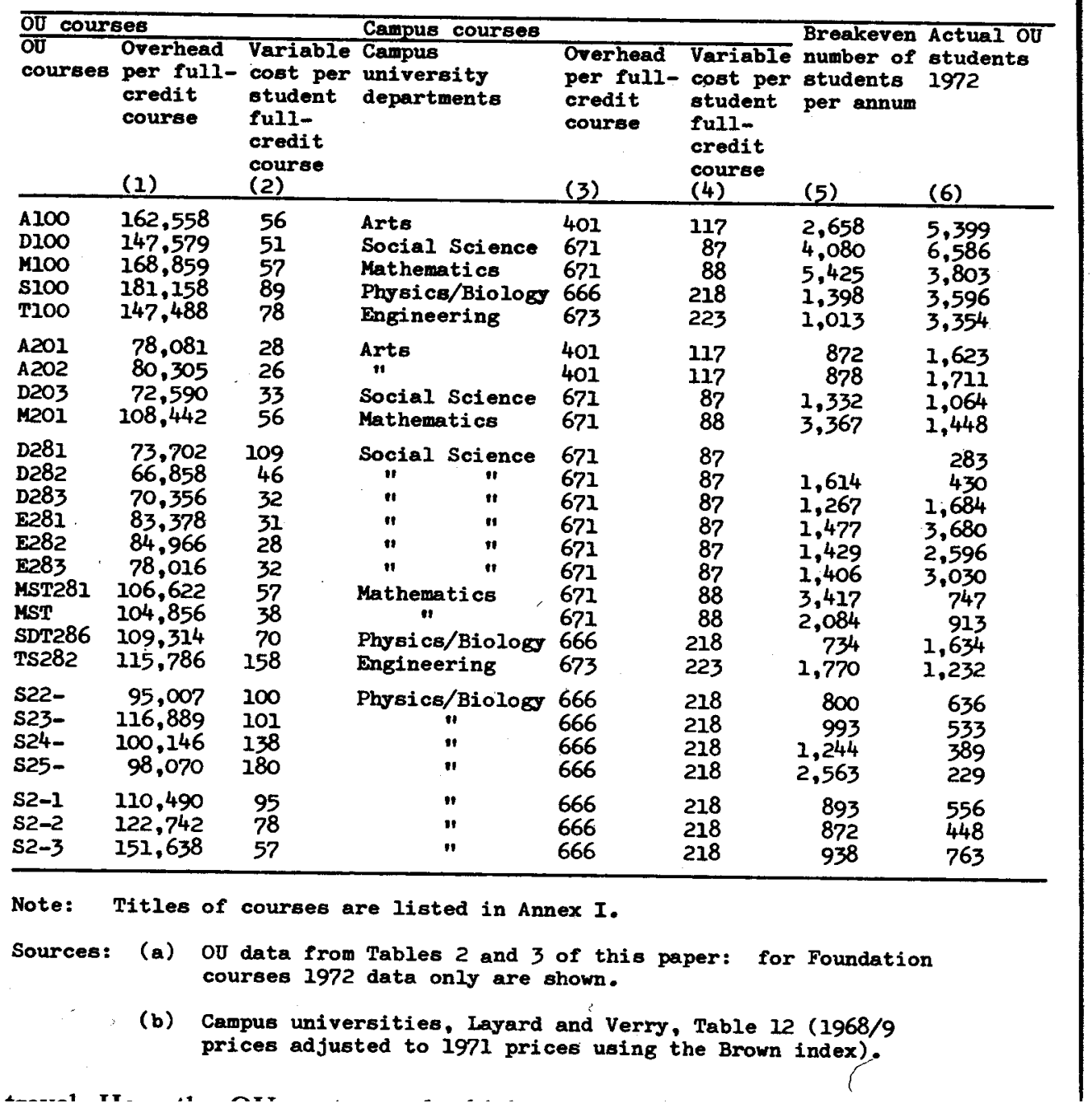

The figures used for campus universities are based on a cross- sectional study of the current costs of all British universities in 1968/69 (Layard and Verry, 1973). Here university costs, as reported to the UGC, were divided into departmental costs and central university costs, com- prising about $63 \%$ and 
Table 7

oU central university costs and central costs in campus universities

\begin{tabular}{lr} 
& $£(1971$ prices $)$ \\
\hline OU & $1,584,247$ \\
Variable per university & 44 \\
Campus universities & 130,935 \\
Overhead per university & 111 \\
Variable cost per OU-equivalent student & 21,691 \\
Breakeven number of students & 31,383 \\
Actual number of students in & \\
\hline
\end{tabular}

(c) Campus universities: Layard and Verry, 19731 Table 12 (1968/9 prices, adjusted to 1971, prices using 'the Brown index)

$37 \%$ of all costs. The departmental costs were in turn divided between the different faculties. Within each faculty, costs were allocated between undergraduates, postgraduates and research in proportion to the time which teachers reported spending on these three activities in the Vice-Chancellors' Committee's diary exercise (CVCP 1972). The undergraduate costs were then regressed on the number of departments in each faculty and its number of students so as to obtain an overhead cost per department and a marginal cost per student. ${ }^{13}$ To obtain figures of cost per student full-credit course the crucial assumption to be made concerns the number of full-credit courses taken by a campus student in a year. Wagner (1972) has followed the UGC in assuming that one full-time student is equivalent to two OU students. Since OU students take on average 1.2 courses a year, a full-time student is therefore assumed to take 2.4 such courses. ${ }^{14}$

Viewed from one angle this may seem to underestimate the comparative output of the OU since an OU ordinary degree is intended to have the same standard as a conventional degree taken after 3 years full-time study, and requires 6 full credits - making 2 courses equal to one full-time student year. On the other hand the OU honours degree requires 8 full credits - making 2.66 courses equal to one full-time student year. An alternative approach altogether

\footnotetext{
1313 The equation within each faculty is: $\mathrm{C}=\mathrm{aD}+\mathrm{bU}$

where $\mathrm{C}$ is undergraduate costs in the university and faculty in question, $D$ is its number of departments and $U$ is its number of undergraduates. Very similar values of $b$ were obtained, where all costs $(T)$ were regressed on $D, U$, postgraduates $(P)$ and teachers' research hours $(R)$ in: $\mathrm{T}=\mathrm{aD}+\mathrm{bU}+\mathrm{cP}+\mathrm{dR}$

1414 The figures in Column (4) are therefore $b / 2.4$ where $b$ is the parameter referred to in the previous footnote.
} 
is to compare the inputs of student time: for OU students 12 hours a week per course at 1.2 courses per student over 44 weeks including revision weeks, i.e. about 630 hours per year. By comparison the conventional undergraduate works some 38 hours per week (Committee on Higher Education, 1963, p. 277) for 30 term-time weeks a year plus say another 120 hours in the vacations, making 1,260 hours a year. On this count the Wagner ratio of 2 OU students to I fulltime student seems reasonable.

We next need an overhead cost per full-credit course in campus universities. This is obtained from the overhead cost per department on the assumption that (a) the number of courses does not vary with the number of students (this is the same as the above assumption that all marginal student costs correspond to variable course costs) and (b) that there are no fixed departmental costs which are not attributable to courses. On these assumptions we simply need to guess the number of courses per department and have guessed 20.15 This is a highly arbitrary procedure but makes a negligible difference to the conclusions of the analysis, as will appear later. ${ }^{16}$ Finally, both fixed and variable current costs are multiplied by 1.25 to allow for the annual cost of equipment of buildings. ${ }^{17} \mathrm{We}$ assume that costs are the same on each undergraduate course which is again highly arbitrary but Bottomley (1972) provides no evidence of any systematic variation over years of the undergraduate course.

The comparison now proceeds as follows. The real strength of the OU teaching system, aside from its social aspects, is the potential economies of scale which can be reaped by substituting capital for labour. This means that a major part of the costs of the course become fixed and invariant with respect to student numbers. The cost function thus has high fixed costs and low marginal costs as illustrated in Figure 1. By contrast campus university courses have low fixed costs but high marginal costs. For low levels of operation the campus university is the more efficient and for high levels the OU system. At some scale there is a breakeven point. These breakeven points are tabulated in Table 6 and compared with OU scales of operation in 1972. The breakeven points are calculated, for example for course A 100 from the equation

$$
162,558+565=401+1175
$$

As can be seen from this example the magnitude represented as 401

\footnotetext{
15 Thus the figures in Column (3) equal a/20.

16 The reason is that most campus costs are treated as variable. It could well be argued that more of campus costs ought to be considered as fixed course costs in which case a comparison of costs per course would be more favourable to the campus universities since a part of their high total cost comes from the wide range of courses they offer.

17 This is the ratio of the total annual cost of full-time higher education to its current cost as reported in Committee on Higher Education (1963) p. 153.
} 
could vary widely with negligible effect on the breakeven points.

Before commenting on the results in Table 6 , we would emphasize that all our data on the Open University relate to its period of initial growth, rather than to the comparative steady state position of campus universities. All the courses covered in this study are in their first presentation life, assumed to last four years. ${ }^{18}$ In a steady state, when the primary, though not exclusive, activity of course production will be concerned with remaking and updating courses that have reached the end of their presentation life, it is expected that central academic faculty costs per course will be up to 50 per cent less than indicated in Table 2.

\section{Figure I}

\section{Illustrative costs per course}

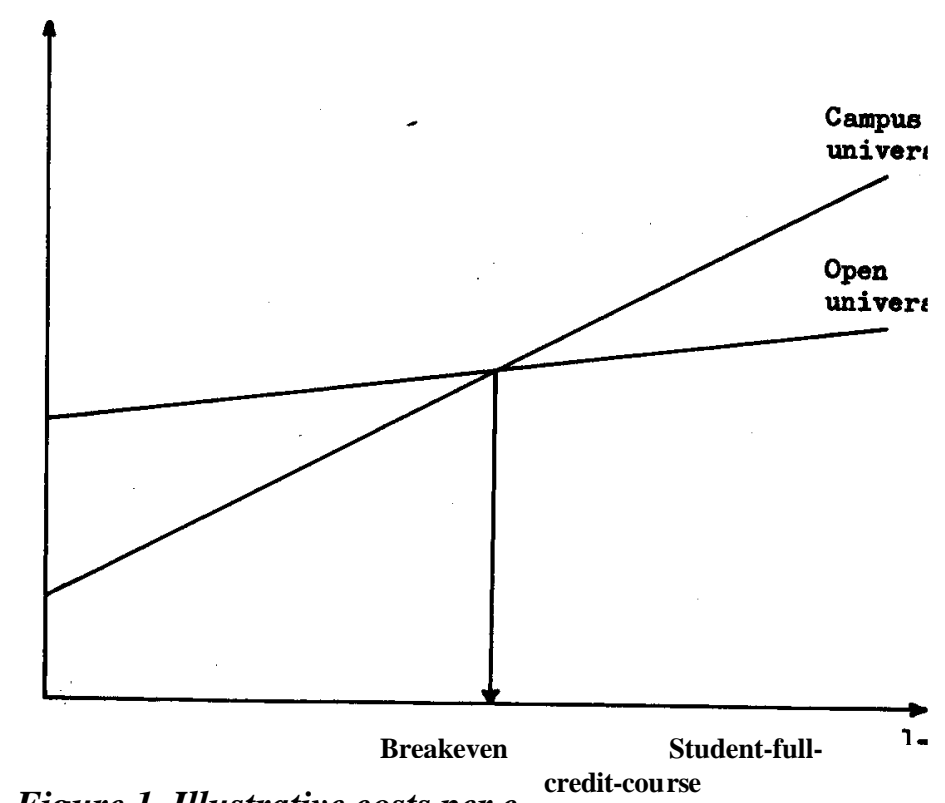

Figure 1. Illustrative costs per $c_{\text {, }}$

On the broadcasting side, the twin limitations of studio capacity for making programmes and available air-time to deliver them will induce a thinning out of the relatively costly broadcasting component of courses. Over a longer time span, both these constraints may be overcome - in production by the construction of an audio-visual centre at Milton Keynes and in delivery by the

\footnotetext{
18 The OU decided in 1973 to extend the presentation life of certain courses beyond four years so reducing, at a stroke, their annual fixed cost. For example, if a course was presented continuously for six years, the annual fixed costs would be reduced by approximately $30 \%$.
} 
use of new methods such as film or video-cassette, or even in the opening of the fourth TV channel to OU broadcasts. However, it is premature to speculate about the overall effects on costs of these changes.

\section{Conclusions}

Turning to our results, the variable cost per student-course is, with one exception, substantially lower in the OU than elsewhere (see Table 6). This constitutes a strong case for the use of existing OU packages in campus universities, especially as campus universities might feel able to dispense with the costs of the summer schools. It also constitutes a case for expansion of existing courses at the OU. As regards the development of new OU packages, the table shows the foundation courses to be much cheaper than equivalent provision de novo at the same scale in campus universities. Measured by the breakeven number of students, second-level courses in a given faculty are cheaper than foundation level courses. But they also have fewer students and some are operating at levels which, if there were no interdependence between courses, might be considered expensive. The table suggests that higher level courses with even fewer students will have to be justified on the ground that they are an integral part of a system providing wider access to complete degree courses rather than on the ground that they are a cheap way of doing this. Alternatively, it may be possible to vary the mix of teaching components, involving a switch from high fixed-cost components such as broadcasting to media of instruction whose cost is largely variable, for example various forms of face-to-face teaching.

To complete the picture we have also to look at central costs. ${ }^{19}$ As Table 7 shows, the variable cost per full-time equivalent student is again substantially lower at the OU than elsewhere - about one half. The size above which the OU has lower central costs per student than a campus university is just two-thirds its present size.

None of this answers the question of whether the OU will prove to have a lower average cost per student or per graduate than campus universities. The outcome of such a calculation depends not only on the cost of its third and fourth level courses and future rates of dropout, but much more profoundly, on the size the Open University is allowed to reach. In any case, as we said at the

\footnotetext{
19 Here the fixed cost (a) and the marginal cost per undergraduate ( $\left.b^{\prime}\right)$ are obtained from the following regression where $C^{u}$ is central university costs, $U^{u}$ is undergraduates in the university, $P^{u}$ is postgraduates and $R^{u}$ staff research hours:

$C^{u}=a^{\prime}+b^{\prime} U^{u}+c^{\prime} P^{u}+d^{\prime} R^{u}$
} 
outset, it is not a particularly relevant question. ${ }^{20}$

As we have stressed, the purpose of this paper is not to evaluate the OU as such but to throw light on the direct costs of different teaching methods irrespective of whether the students are home- or campus-based. However, there is always the danger of misinterpretation. So we end by considering the implications of the fact that OU students are home-based. This means, or is generally thought to mean, that their study time displaces leisure time, whereas the study time of campus students displaces working time. Assuming the study time is the same for both types of students, which is the more costly? Only a crass materialist would argue that no cost would be involved in the reduction of leisure. However, many students may prefer study to their alternative leisure activities. If OU students were indeed indifferent between study and leisure and campus students indifferent between study and work, then a campus studentcourse would have an additional differential cost equal to the foregone work output of the campus student. This, at 630 hours per student-course and $£ 0.75$ output per hour, gives a cost of $£ 473$ per student-course. If this is added to the figures in Column (4) of Table 6 we get the quite different set of breakeven numbers shown in Table 8 . However we must stress again that this table embodies a set of extreme assumptions. It assumes (a) that OU students experience no net cost of leisure foregone; (b) that campus students would like working as much as being students. More important, our aim has not been to compare off- campus and on-campus teaching systems, but rather those that depend on capital-intensive packages with those that depend on labour-intensive live instruction. Our conclusions on this latter comparison were given in the previous paragraphs.

\footnotetext{
20 For those interested in irrelevant questions we provide the following information. If the OU students of 1972 had received their instruction by campus methods (in, say, three extra campus universities) the annual cost would have been $£ 10,144,000$. The actual annual cost, again using the data in Tables 6 and 7 was $£ 8,562,000$. If the production foregone referred to in the next paragraph is added in, the campus cost would have been $£ 32,998,000$.
} 


\section{TABLE 8}

Breakeven, number of students making extra allowance for output foregone by campus students

\begin{tabular}{llr} 
OU courses & $\begin{array}{l}\text { Breakeven number of } \\
\text { student per annum }\end{array}$ & Actual OU students \\
\hline A100 & 275 & 5,399 \\
D100 & 263 & 6,586 \\
M100 & 300 & 3,803 \\
S100 & 261 & 3,596 \\
T100 & 211 & 3,354 \\
A201 & 132 & 1,623 \\
A202 & 136 & 1,711 \\
D203 & 129 & 1,064 \\
M201 & 192 & 1,448 \\
D281 & 131 & 283 \\
D282 & 118 & 430 \\
D283 & 125 & 1,684 \\
E281 & 148 & 3,680 \\
E282 & 151 & 2,596 \\
E283 & 138 & 3,030 \\
MST281 & 189 & 747 \\
MST282 & 186 & 913 \\
SDT286 & 157 & 1,634 \\
TS282 & 166 & 1,232 \\
S22- & 137 & 636 \\
S23- & 168 & 533 \\
S24- & 144 & 389 \\
S25- & 141 & 229 \\
S2-1 & 159 & 556 \\
S2-2 & 177 & 448 \\
S2-3 & 219 & \\
\hline
\end{tabular}

\section{References}

Blacklock, S. and Momson, V. (1972). "Students' workload," Open University.(Mimeo).

Bottomley, A. (1972). Costs and Potential Economies. Paris: OECD. Centre for Educational Research and Innovation. 
Committee on Higher Education (1963). Higher Education. (Robbins Report). Appendix Two (B) and Appendix Four. London: HMSO. Cmnd. 2154.

Committee of Vice-Chancellors and Principals (1972). Report of an Enquiry into the Use of Academic Staff Time. London: CVCP.

Esmee Fairbairn Economics Research Centre (1972). Efficiency in Higher Education. Vol. 2.

Layard, P. R. G. (1973). 'The "New Media and Higher Education," Minerva (April).

Layard, P. R. G. andVerry, D. (1973). Cost Functions for Teaching and Research in UK Universities, London School of Economics, Higher Education Research Unit. (Mimeo).

Mcintosh, N. and Morrison,V. (1972). "Students' study habits and their reactions to Foundation Course materials." Open University (Mimeo).

Wagner, L. (1972). "The Economics of the Open University," Higher Education 1. 2:159-183.

Wagner, L. (1973). "The Open University and the costs of expanding higher education," Universities Quarterly (Autumn). 